\title{
Cardiology Approach to Kawasaki Disease
}

\section{Samah Alasrawi*}

Pediatric Cardiologist, AlJalila Children Heart Center, Dubai, UAE

*Corresponding Author: Samah Alasrawi, Pediatric Cardiologist, AlJalila Children Heart Center, Dubai, UAE

Received: September 27, 2019; Published: October 15, 2019

\begin{abstract}
Objectives: Kawasaki disease is an acute multi system vasculitis affects large and medium sized vessels of childhood, So, it can affect the coronary arteries, in this article we will focus on the cardiology approach to Kawasaki disease.

We will go through Investigations: Echo cardiography, stress test and catheterization, then the treatment and follow up for Kawasaki disease patients.

Conclusion: Kawasaki disease is a common childhood systemic vasculitis characterized by specific clinical features. Transthoracic echocardiography is recommended in suspected cases of Kawasaki disease, however a normal study does not exclude the diagnosis. Treatment with high dose intravenous immunoglobulin should be initiated based on the clinical presentation and should not be delayed by the timing of echocardiography.
\end{abstract}

Keywords: Kawasaki Disease; Cardiology; Approach

\section{Introduction}

Kawasaki disease is an acute self-system vasculitis affects large and medium sized vessels of childhood.

Characterized by: Fever, Bilateral non exudative conjunctivitis

Erythema of the lips and oral mucosa, Changes in the extremities, Rash, Cervical lymphadenopathy

- The leading cause for acquired heart disease in children

- Coronary artery aneurysms or ectasia develop in $15 \%$ to $25 \%$ of untreated children and can lead to ischemic heart disease or

Sudden death

- $\quad$ Age of onset: Peak age - 2 to 5 years, $80-85 \%<5$ years, rare $>11$ years.

Cardiac complications of Kawasaki disease

- $\quad$ About $1 / 3$ of untreated KD patients develop coronary artery abnormalities.

- Half of coronary artery lesions regress within five years, and in most with mild aneurism (3-4 $\mathrm{mm})$ regress within two years.
But giant aneurysms ( $>8 \mathrm{~mm}$ ) don't resolve most of the time, and some may develop stenosis.

\section{Echocardiography in Kawasaki disease}

Echocardiography is used for the diagnosis of coronary artery lesions, it is sensitive and specific tool, and should be done in confirmed or suspected cases of Kawasaki disease at the time of diagnosis.

Treatment is recommended when there is a clinical presentation for Kawasaki disease, and should not be delayed until we do the echocardiography.

But if full clinical criteria are not met and there are coronary artery lesions on echocardiography, then the child has incomplete features of Kawasaki disease and we have to treat.

The main aim of echocardiography in Kawasaki disease is to identify coronary artery lesions, and the other inflammation process in the heart like pericarditis and/or myocarditis. 
We can evaluate the coronary arteries from parasternal short axis which allows to see the left coronary artery origin, left anterior descending artery and left circumflex artery, as well as the right coronary artery (Figure 1, 2).

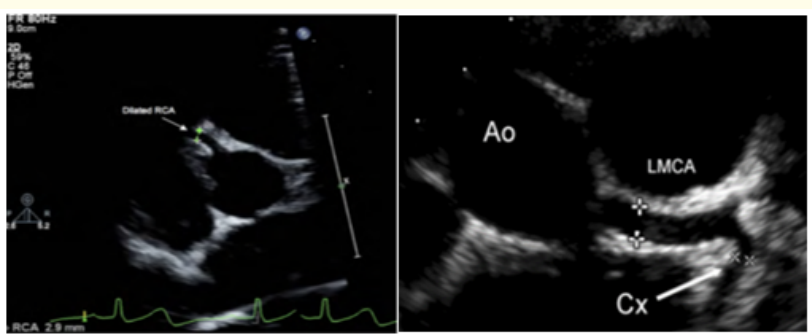

Figure 1: Short axis view showed in the left: dilated right coronary artery, in the right: dilated left coronary artery.

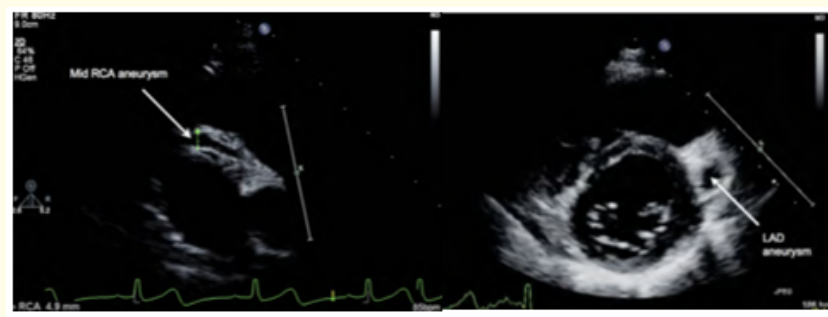

Figure 2: Short axis view showed in the left: right coronary artery aneurysm, in the Right: left coronary artery aneurysm.

\section{Timing of echocardiography}

The recommendations are to perform echocardiography at diagnosis, then after 2 weeks and repeating at 6-8 weeks after the onset of clinical features for uncomplicated cases.

The baseline study should be done at diagnosis for left ventricular function, coronary arterial lesions, valvar involvement, myocardial and/or pericardial involvement.

If there is any cardiac involvement closer follow up is required.

When the coronary aneurysms $>5 \mathrm{~mm}$ this will elevate risk of developing stenotic coronaries so it will require close monitoring.

Transient cardiac involvement is likely to have resolved by 6 to 8 weeks, or if coronary artery dilation and/or aneurysms are pres- ent, the maximum diameter is usually reached by 6 to 8 weeks also, because that we do follow up Echo at this time.

\section{Coronary artery involvement}

Coronary artery lesions are perivascular brightness, dilatation, aneurysm formation, and lack of tapering of the distal coronary vessel (Figure 1, 2).

Aneurysms forms: (Figure 3)

Fusiform (spindle-shaped),

Saccular (spherical),

Ectatic (uniformly dilated long segment) or

Segmented (multiple dilatations joined by normal or stenotic areas)

*classification was first published in 1984. Aneurysms according to internal diameter are considered to be Small if $<5 \mathrm{~mm}$

Medium if between 5-8mm,

Giant if $>8 \mathrm{~mm}$

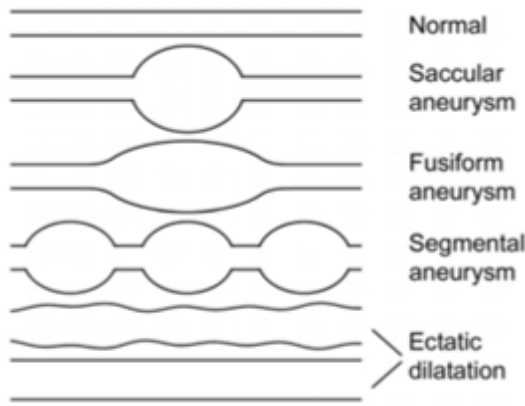

Figure 3: Coronary artery abnormalities.

\section{Myocarditis-pericarditis}

- Virtually all patients with Kawasaki disease develop myocarditis to varying degrees during the acute phase, and over half of these patients develop acute transient left ventricular dysfunction.

- Pericardial involvement may be pericarditis with/without pericardial effusion.

- Mild mitral, tricuspid or aortic regurgitation maybe caused by myocardial inflammation.

Further imaging modalities

Coronary artery imaging difficulties increases with age, so other imaging options may be used like resonance imaging and multi- 
detector computed tomography. Especially that echocardiography has its limitations in diagnosis of stenosis and thrombosis.

\section{Functional assessment}

Cardiac stress testing may be used to identify reversible ischemia and regional wall motion abnormalities during increased demand.

Coronary perfusion abnormalities can be further assessed with exercise echocardiography, pharmacologic (dobutamine, dipyridamole or adenosine) stress echocardiography and exercise myocardial perfusion scans.

\section{Cardiac catheterization}

Cardiac catheterization with selective coronary angiography is considered the gold standard for delineation of coronary artery anatomy, and if required interventional procedures such balloon angioplasty, stent placement or percutaneous transluminal coronary revascularization may be performed in the same setting.

Cardiac catheterization is usually recommended for patients with complex coronary artery lesions however it can provide useful detailed information and help with risk stratification but with mild coronary artery lesion it is not recommended.

Coronary angiography in this instance is recommended 6-12 months after the onset of Kawasaki disease, or sooner as clinically indicated [1-9].

Risk stratification (Table 2)
Recommended guideline for the management of Kawasaki disease in the UK

Treatment

- IVIG $2 \mathrm{~g} / \mathrm{kg}$ as a single infusion over 12 hours

- Aspirin 30-50 mg/kg/day in 4 divided doses for 2 weeks (7.5 - $12.5 \mathrm{mg} / \mathrm{kg}$ QDS)

- Echocardiography and ECG

- Aspirin 2-5 mg/kg/day when fever settled (disease defervescence) continuing for a minimum of 6 weeks (Table 1).

\begin{tabular}{|c|c|c|}
\hline \multicolumn{3}{|c|}{ Repeat echocardiography at 2 and 6 weeks } \\
\hline No CAA & CAA $<8 \mathrm{~mm}$, no stenoses & $C A A>8 \mathrm{~mm}$ and/or stenoses \\
\hline $\begin{array}{l}\text { Stop aspirin at } 6 \\
\text { weeks }\end{array}$ & Continue aspirin & Lifelong aspirin $2-5 \mathrm{mg} / \mathrm{kg} / \mathrm{day}$ \\
\hline \multirow[t]{5}{*}{$\begin{array}{l}\text { Lifelong follow up at } \\
\text { least every } 2 \text { years }\end{array}$} & $\begin{array}{l}\text { Repeat echocardiography and } \\
\text { ECG at } 6 \text { monthly intervals }\end{array}$ & Consider warfarin \\
\hline & Discontinue aspirin if resolves & $\begin{array}{l}\text { Consider coronary aneurysm } \\
\text { angiography and exercise stress } \\
\text { testing }\end{array}$ \\
\hline & $\begin{array}{l}\text { Consider exercise stress test if } \\
\text { multiple aneurysms }\end{array}$ & $\begin{array}{l}\text { Repeat echocardiography and ECG at } \\
6 \text { monthly intervals }\end{array}$ \\
\hline & $\begin{array}{l}\text { Specific advice on minimizing } \\
\text { atheroma risk factors }\end{array}$ & $\begin{array}{l}\text { Specific advice on minimizing } \\
\text { atheroma risk factors }\end{array}$ \\
\hline & Lifelong follow up & Lifelong follow up \\
\hline
\end{tabular}

No disease defervescence within $\mathbf{4 8}$ hours, or disease recrudescence within 2

Second dose of $1 V I G$ at $2 \mathrm{gm} / \mathrm{kg} / \mathrm{day}$

Second dose of $I V I G$ at $2 \mathrm{gm} / \mathrm{kg} / \mathrm{day}$
Pulsed methylprednisolone at $600 \mathrm{mg} / \mathrm{m} 2$ twice daily for 3 days or

Table 1: Treatment and follow up according to the coronary arteries involvements.

\begin{tabular}{|c|c|c|c|c|}
\hline Risk Level & $\begin{array}{l}\text { Pharmacological } \\
\text { Therapy }\end{array}$ & Physical Activity & $\begin{array}{l}\text { Follow-Up and } \\
\text { Diagnostic Testing }\end{array}$ & Invasive Testing \\
\hline $\begin{array}{c}\text { I (no coronary artery } \\
\text { changes at any stage of } \\
\text { illness) }\end{array}$ & None beyond 1 st $6-8$ weeks & $\begin{array}{c}\text { No restrictions beyond } 1 \text { st } 6- \\
8 \text { weeks }\end{array}$ & $\begin{array}{c}\text { Cardiovascular risk } \\
\text { assessment, counseling at } \\
5-\mathrm{y} \text { intervals }\end{array}$ & None recommended \\
\hline $\begin{array}{l}\text { II (transient coronary } \\
\text { artery ectasia disappears } \\
\text { within 1st 6-8 weeks) }\end{array}$ & None beyond 1 st $6-8$ weeks & $\begin{array}{c}\text { No restrictions beyond } 1 \text { st } 6- \\
8 \text { weeks }\end{array}$ & $\begin{array}{c}\text { Cardiovascular risk } \\
\text { assessment, counseling at } \\
\text { 3- to 5-y intervals }\end{array}$ & None recommended \\
\hline $\begin{array}{c}\text { III (1 small-medium } \\
\text { coronary artery } \\
\text { aneurysm/major coronary } \\
\text { artery) }\end{array}$ & $\begin{array}{l}\text { Low-dose aspirin ( } 3-5 \\
\mathrm{mg} / \mathrm{kg} \text { aspirin } / \mathrm{d}), \text { at least } \\
\text { until aneurysm regression } \\
\text { documented }\end{array}$ & $\begin{array}{c}\text { For patients }<11 \text { y old, no } \\
\text { restriction beyond } 1 \text { st } 6-8 \\
\text { weeks; patients } 11-20 \text { y old, } \\
\text { physical activity guided by } \\
\text { biennial stress test, } \\
\text { evaluation of myocardial } \\
\text { perfusion scan; contact or } \\
\text { high-impact sports } \\
\text { discouraged for patients } \\
\text { taking antiplatelet agents }\end{array}$ & $\begin{array}{l}\text { Annual cardiology follow-up } \\
\text { with echocardiogram }+ \\
\text { ECG, combined with } \\
\text { cardiovascular risk } \\
\text { assessment, counseling; } \\
\text { biennial stress test/evaluation } \\
\text { of myocardial perfusion scan }\end{array}$ & $\begin{array}{l}\text { Angiography, if noninvasive } \\
\text { test suggests ischemia }\end{array}$ \\
\hline $\begin{array}{l}\text { IV large or giant coronary } \\
\text { artery aneurysm, or } \\
\text { multiple or complex } \\
\text { aneurysms in same } \\
\text { coronary artery, without } \\
\text { obstruction) }\end{array}$ & $\begin{array}{l}\text { Long-term antiplatelet } \\
\text { therapy and Warfarin (target } \\
\text { INR } 2.0-2.5 \text { ) or low- } \\
\text { molecular-weight heparin } \\
\text { (target: antifactor Xa leve1 } \\
0.5-1.0 \mathrm{U} / \mathrm{mL} \text { ) should be } \\
\text { combined in giant aneurysms }\end{array}$ & $\begin{array}{l}\text { Contact or high-impact } \\
\text { sports should be avoided } \\
\text { because of risk of bleeding; } \\
\text { other physical activity } \\
\text { recommendations guided by } \\
\text { stress test/evaluation of } \\
\text { myocardial perfusion scan } \\
\text { outcome }\end{array}$ & $\begin{array}{l}\text { Biannual follow-up with } \\
\text { echocardiogram + ECG; } \\
\text { annual stress test/evaluation } \\
\text { of myocardial perfusion scan }\end{array}$ & $\begin{array}{c}\text { 1st angiography at } 6-12 \mathrm{mo} \\
\text { or sooner if clinically } \\
\text { indicated; repeated } \\
\text { angiography if noninvasive } \\
\text { test, clinical, or laboratory } \\
\text { findings suggest ischemia; } \\
\text { elective repeat angiography } \\
\text { under some circumstances } \\
\text { (see text) }\end{array}$ \\
\hline $\begin{array}{l}\mathrm{V} \text { (coronary artery } \\
\text { obstruction) }\end{array}$ & $\begin{array}{l}\text { Long-term low-dose aspirin; } \\
\text { warfarin or low-molecular- } \\
\text { weight heparin if giant } \\
\text { aneurysm persists; consider } \\
\text { use of } \mathrm{B} \text {-blockers to reduce } \\
\text { myocardial } \mathrm{O}_{2} \text { consumption }\end{array}$ & $\begin{array}{l}\text { Contact or high-impact } \\
\text { sports should be avoided } \\
\text { because of risk of bleeding; } \\
\text { other physical activity } \\
\text { recommendations guided by } \\
\text { stress test/myocardial } \\
\text { perfusion scan outcome }\end{array}$ & $\begin{array}{l}\text { Biannual follow-up with } \\
\text { echocardiogram and ECG; } \\
\text { annual stress test/evaluation } \\
\text { of myocardial perfusion scan }\end{array}$ & $\begin{array}{c}\text { Angiography recommended } \\
\text { to address therapeutic } \\
\text { options }\end{array}$ \\
\hline
\end{tabular}

Table 2 


\section{Conclusion}

- Kawasaki disease is a common childhood systemic vasculitis characterized by specific clinical features and persistent fever for at least 5 days.

- We have to do echocardiography for suspected cases of Kawasaki disease, and to put in mind that a normal study does not exclude the diagnosis of Kawasaki.

- When there is a clinical features of Kawasaki disease, treatment with high dose intravenous immunoglobulin is recommended and should not be postponded until we do the echocardiography.

- The main aim of echocardiography in Kawasaki disease is to identify coronary artery lesions, function and the other inflammation process in the heart like pericarditis and/ or myocarditis.

- The recommendations are to perform echocardiography at diagnosis, then after 2 weeks and repeating at 6-8 weeks after the onset of clinical features for uncomplicated cases, with more frequent follow up if there is cardiac involvement.

\section{Bibliography}

1. Ajami G., et al. "Evaluation of myocardial function using the Tei index in patients with Kawasaki disease". Cardiology in the Young 20 (2010): 44-48.

2. Akagi T., et al. "Valvular heart disease in Kawasaki syndrome: incidence and natural history". American Heart Journal 120 (1990): 366-372.

3. Burgner D and Harnden A. "Kawasaki disease: what is the epidemiology telling us about the etiology?" International Journal of Infectious Diseases 9 (2005): 185-194.

4. Cheung Y., et al. "Relationship between carotid intima-media thickness and arterial stiffness in children after Kawasaki disease". Archives of Disease in Childhood 92 (2007): 43-47.

5. Harnden A., et al. "Kawasaki disease”. BMJ 338 (2009): b1514.

6. Dominguez, S., et al. "Kawasaki disease in a pediatric intensive care unit: a case-control study". Pediatrics 122 (2008): e786790.

7. Duerinckx, A., et al. "Coronary MR angiography in Kawasaki disease”. American Journal of Roentgenology 168 (1997): 114116.
8. Fujita Y., et al. "Kawasaki disease in families". Pediatrics 84 (1989): 666-669.

9. Genizi J., et al. "Kawasaki disease in very young infants: high prevalence of atypical presentation and coronary arteritis". Clinical Pediatrics (Phila) 42 (2003): 263-267.

\section{Volume 2 Issue 11 November 2019}

\section{(C) All rights are reserved by Samah Alasrawi.}

